\title{
Editorial business
}

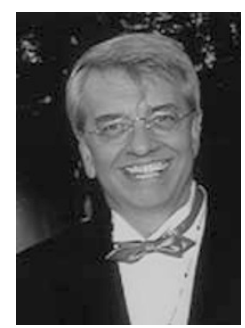

JJ Wyndaele, Editor

Antwerp University Hospital, Antwerp, Belgium

E-mail: spinalcord@uza.be

Dear Spinal Cord reader,

I think that the moment is right to explain some aspects of the Spinal Cord editorial process, including submission, peer-review, and making a final decision on a manuscript.

Spinal Cord aims to publish the highest level of scientific work performed in the field of spinal cord care. Manuscripts can be original studies or case reports. Reviews are of special interest because they give an overview of what has been published on a specific topic, evaluated by the authors into a conclusion on the current research state - what has been well or less well proven and where would extra research be worthwhile. Review articles have to be presented to the Editor in Chief first; I will then decide if such work would be of interest to Spinal Cord readers and accept or decline the offer of submitting. In other instances I can approach authors myself to commission a review on a specific topic of interest.

When a manuscript enters the electronic submission process, Cathy Mallentjer, at the Antwerp Editorial Office first checks if all requested material is present and is written according to the instructions to authors. If everything complies, the manuscript can enter the review process. If material is missing, the number of references is too high, or the word count is over the limit, Cathy will ask the authors to correct the problem before entering the revised manuscript for review. When a manuscript enters the review folder the list of possible reviewers is consulted and reviewers are invited electronically: in principle two for case reports, three for original manuscripts, and four for review manuscripts.

A time period for reviewing a manuscript is allocated. When comments from reviewers are entered online the editor is notified and when all requested comments have been submitted, the final decision is made. Such decision making will be guided for a great part by the comments of the reviewers. Reviewers are also asked if they think the manuscript would benefit from an editorial note being published with the paper. These are designed to provide some extra information and thoughts about the subject and the way it was investigated.

Letters to the editor are sent mostly as reactions to work published in Spinal Cord. If found interesting, the letter is forwarded to the authors of the original manuscript. The letter and the reply of the original authors are published together in the journal. Resubmitted work, after revisions have been completed, is usually sent back to the original reviewers for further comments.

Why some manuscripts are accepted and others turned down is the result of the rather elaborate process explained above. But, because of restricted pagination and the ever growing number of submissions, there is a need to grade the submissions and accept only those whose position in the grading is high enough to warrant publication. Being an author myself I am fully aware how disappointing it is when one's paper is rejected. However the reviewer's comments usually help to make it a better paper, to offer guidance to improve the methodology and data evaluation, which can lead to work of much higher quality.

This process of submission, waiting for the comments of reviewers, and resubmission of revised work that is then re-reviewed takes time. A big effort is made to keep this time as short as possible.

It is our experience that the Antwerp Spinal Cord Editorial Office has a lively communication with the authors and the readers. Please contact us without hesitation to discuss your work, ask advice or comment on what we do.

In this issue there are very interesting contributions on major topics. Enjoy reading. 